\title{
Study of Diffusion, Kinetics of Sintering, Structure and Properties in Powder Steels with Free and Spark Plasma Sintering
}

\section{S. A. Oglezneva and K. L. Saenkov}

Science Center of Powder Material Science of Perm National Research Polytechnic Univercity, 6 Professora Pozdeeva street, Perm, 614013, Russia

\section{Abstract}

The diffusion processes and sintering kinetics in micro- and nanodispersed "Fe-Ni" powder systems during sintering in $\alpha$ - and $\gamma$-regions with free and spark plasma sintering (SPS), as well as the structure and properties of metastable powder steels on the basis of these systems are studied. The diffusion coefficient $(D)$ in iron-nickel systems was 2-3 times higher in systems with nanodispersed nickel powder than in

Corresponding Author: S. A. Oglezneva osa@pm.pstu.ru

Received: 21 December 2017 Accepted: 15 April 2018

Published: 6 May 2018

Publishing services provided by Knowledge E

(c) S. A. Oglezneva and K. L. Saenkov. This article is

distributed under the terms of the Creative Commons

Attribution License, which permits unrestricted use and redistribution provided that the original author and source are credited.

Selection and Peer-review under the responsibility of the MIE-2017 Conference Committee.

\section{G OPEN ACCESS}

the system with microdispersed powder. The SPS provides, at lower temperatures and a time, an increase of $D$ by an order of magnitude or more, compared to free sintering. The coefficients of the equation of the Ivensen sintering kinetics are calculated. The use of SPS for the iron-nickel powder system significantly reduced the activation energy of sintering. In the SPS process, as in free sintering, in the carbide steels of the "iron-nickel-titanium carbide" system, a ferrite-austenite structure is formed in which, after abrasion friction, a metastable austenite is transformed into a martensite of deformation, while the volume of conversion is larger, the higher were the hardness, microhardness and wear resistance. The use of nanodispersed powders of nickel and titanium carbide for the manufacture of diamond tools have improved its cutting ability.

\section{INTRODUCTION}

Cutting and grinding tools with metal bond, is the most sought after tools for processing non-metallic materials (natural stone, building materials, fig. 1), as it has high thermal conductivity, wear resistance, provides high speed grinding [1]. One of the effective methods of manufacturing the composite powder of diamond tools is powder metallurgy. The improved properties of the composite material can be achieved through the use of nanodispersed metal powders [2]. However, the consolidation of nanosized powders typically require sintering with the application of pressure, such as plasmaspark sintering $[3,4]$. Another way of improving the properties - the formation of the structure of metastable austenite [5], which is in the process of the work hardened due 
to the formation of deformation martensite [6] that as a result improves the fixation of the diamond grains increases the strength of the ligaments and cutting properties of the tool [5].

The work purpose is research of structure and properties of powder bonds for diamond tools of systems, "Fe - Ni" on the basis of the fine iron powder and micro - and nanodispersed powders of Nickel and titanium carbide with the sintering and spark plasma sintering (SPS) and carbidsteels "Fe - Ni - TiC" and the diamond tool "Fe - $\mathrm{Ni}-$ $\mathrm{TiC}-\mathrm{C}$ (diamond)".

\section{EXPERIMENTAL PROCEDURE}

Samples were made from powder mixtures that contain 6-18 wt. \% Nickel, 8 wt. percent titanium carbide, 7,5 wt. \% of diamond grains, the rest is iron. It have been used as the basis of carbonyl iron powder with an average size of 5 microns; the titanium carbide powders: the first, made by the carbothermically with an average size of 5 microns, and the second, obtained by the method of the explosive mechanochemical synthesis in a planetary mill from titanium and graphite. It has been added powders of nickel carbonyl PNK - UT3 with sizes of 3-5 $\mu \mathrm{m}$ or nanosized with the size 50-80 nm, restored salt, as well as synthetic diamond powder AC 32 400/315. Mixture of powders was mixed in a mixer for 8 hours. Then the powders were pressed at a pressure of $400 \mathrm{MPa}$ and were annealed for removing internal stresses in hydrogen for 2 hours at a temperature of $600{ }^{\circ} \mathrm{C}$, the samples were then re-extruded to reduce porosity at a pressure of $600 \mathrm{MPa}$ and sintered finally in hydrogen for 5 hours at a temperature of 900-950 ${ }^{\circ} \mathrm{C}$.

Diffusion couples "iron-nickel" extruded at a pressure of $600 \mathrm{MPa}$. Sintering was conducted at temperatures of 800,900 and $1100{ }^{\circ} \mathrm{C}$, using thermo-mechanical analyzer (dilatometer) Setaram (France) in argon atmosphere under a load of $0.07 \mathrm{MPa}$, and the installation of the spark plasma sintering Dr. Synter SPS-1050b in argon atmosphere at temperatures of $800-900{ }^{\circ} \mathrm{C}$ and a pressure of $30 \mathrm{MPa}$, exposure $5 \mathrm{~min}$. Diffusion coefficients were calculated by the method of Matano-Boltzmann. The coefficient of variation in the concentration of nickel was determined as the ratio of the concentration dispersion related to its average value. Description of the sintering kinetics was carried out according to the empirical equation of V.A. Ivencen (1):

$$
V=V_{\mathscr{H}}(q m \tau+1)^{-1 / m}
$$

where $V, V_{\mathscr{H}}$ - are the pore volumes at the current time of sintering and at the beginning of isothermal aging, $q$-const, the physical meaning of which is the relative 
reduction in pore volume at the time of isothermal sintering, $h^{-1}, m$-const, whose physical meaning is the characteristic intensity of reduction in the rate of reduction in pore volume with sintering time (dimensionless), $\mathrm{T}$ - isothermal aging time in sintering, $h$.

The concentration of elements was determined using an analytical field emission scanning electron microscope ULTRA 55/60 Carl Zaiss with an energy dispersive analyzer. Sintered samples were tested on density and calculated porosity, the HRC hardness, microhardness, strength in three-point bending specimens without cracks according to standard procedures on 3 samples per point, and measurement error was $10 \%$. The study of microstructure was performed on thin sections, etched in nital, using the metallographic microscope Carl Zeiss Axiovert 40MAT by increasing 100200. X-ray phase analysis was performed using the Shimadzu XRD - 6000 in the K $\alpha$ radiation of Cu c Ni filter. Tribological tests were carried out on the friction machine SMTS -2 at a frequency of $300 \mathrm{rpm}$. Steels and diamond tools were tested on the wear by friction on the counterbody of corundum, we calculated the relative wear as a ratio of loss of mass of the sample and the counterbody [5].

\section{EXPERIMENTAL RESULTS}

The diffusion coefficient $(D)$ in the "Fe - $\mathrm{Ni}^{\prime \prime}$ as with micro-dispersed and nanodispersed powder of nckel, at a temperature near the phase transformation in iron $\left(900{ }^{\circ} \mathrm{C}\right.$ ) was higher than that at $1100{ }^{\circ} \mathrm{C}$, fig.1, tab.1. In systems with nano-sized particles of nikel powder $D$ at temperatures of 900 and $1100{ }^{\circ} \mathrm{C}$ were $2-3$ times higher than in the system with the ultrafine powder. SPS provides increase in $D$ by an order of magnitude in comparison with the free sintering at more lower temperatures and the 5 -minute time. When the temperature SPS was increased from 800 to $900{ }^{\circ} \mathrm{C}$, the diffusion coefficient increased about 2 times. The calculated coefficients of the equation of kinetics of sintering of Evensen, tab. 2. The addition of nanosized Nickel powder to micron-sized powder of iron lowers the activation energy several times, with 45 to $7 \mathrm{~kJ} / \mathrm{mol}$. The use of SPS for the system powders "iron-nikel" significantly lowers the activation energy of sintering by maintaining a high concentration of structural defects to the beginning of isothermal sintering at high heating rate and the application of pressure in the process of consolidation (of 5.2 and $3.6 \mathrm{~kJ} / \mathrm{mol}$ for the system with the ultrafine powder of Nickel and nano-dispersed, respectively). The values of the coefficients of the equation of kinetics of sintering confirm that intense shrinkage occurs already during heating; and sintering under pressure during isothermal exposure is much more intense. 


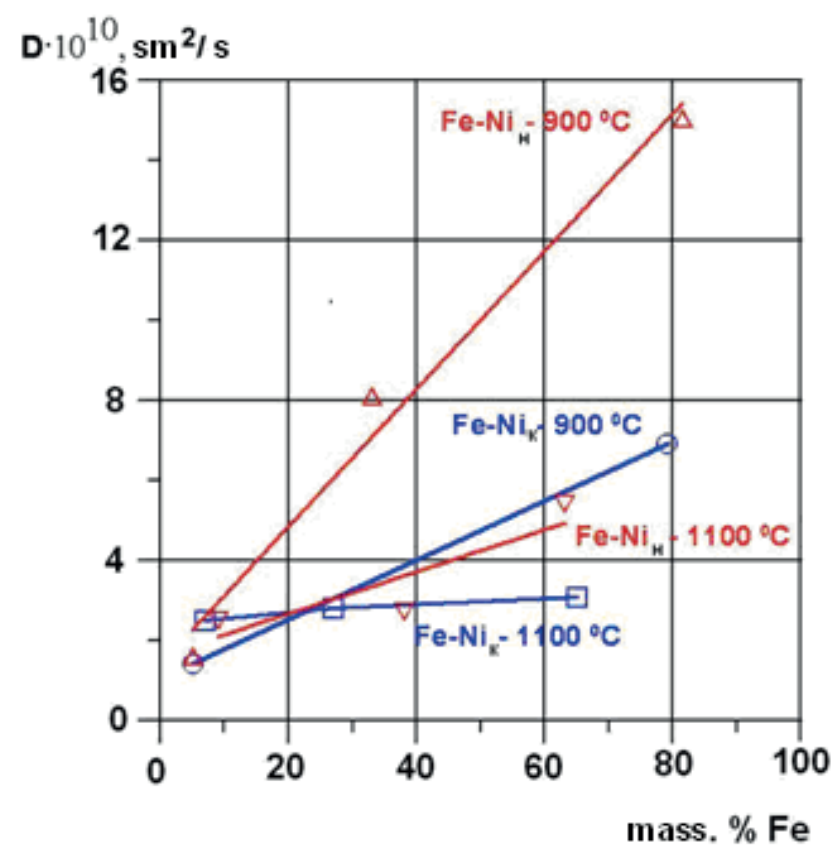

Figure 1: Coefficient of mutual diffusion in iron-nickel systems in the range of iron concentrations $\mathrm{Ni}_{\mathscr{H}}$ particle size $50 \mathrm{~nm}, \mathrm{Ni}$ - particle size $5 \mu \mathrm{m}$, Fe - particle size $5 \mu \mathrm{m}$

TABLE 1: Coefficient of mutual diffusion in iron-nickel systems, $D \cdot 10^{-10}, \mathrm{sm}^{2} / \mathrm{s}$.

\begin{tabular}{|c|c|c|c|c|}
\hline Systems of powders & \multicolumn{2}{|c|}{ Sintering } & \multicolumn{2}{c}{ SPS } \\
\cline { 1 - 4 } $900{ }^{\circ} \mathrm{C}, 6 \mathrm{~h}$ & $1100{ }^{\circ} \mathrm{C}, 6 \mathrm{~h}$ & $\begin{array}{c}800{ }^{\circ} \mathrm{C}, 5 \\
\min \end{array}$ & $900{ }^{\circ} \mathrm{C}, 5 \mathrm{~min}$ \\
\hline $\mathrm{Fe}(5 \mathrm{mkm})-\mathrm{Ni}(5 \mathrm{mkm})$ & 7,0 & 3,2 & 2,9 & 6,8 \\
\hline $\mathrm{Fe}(5 \mathrm{mkm})-\mathrm{Ni}(50 \mathrm{~nm})$ & 14,3 & 4,5 & 4,4 & 7,9 \\
\hline $\mathrm{Fe}(50 \mathrm{~nm})-\mathrm{Ni}(5 \mathrm{mkm})$ & - & - & 4,7 & 5,5 \\
\hline $\mathrm{Fe}(50 \mathrm{~nm})-\mathrm{Ni}(50 \mathrm{~nm})$ & - & - & 5,7 & 5,5
\end{tabular}

When you add the powder titanium carbide to the system of powders of iron and Nickel activation energy of sintering increases by 10 times when the free sintering due to the reduction of area of metallic contact is $85 \mathrm{~kJ} / \mathrm{mol}$, while at SPS is only 2 times (uP to $11 \mathrm{~kJ} / \mathrm{mol}$ ). Grain size in the sintering composition materials, contain nanodispersed powders of nikel and titanium carbide was $4 \mu \mathrm{m}$, with the ultrafine additives - $8 \mu \mathrm{m}$.

In the process of SPS, as with the free sintering, in system "iron-nickel-titanium carbide" is formed by ferrite-austenitic structure with different coefficient of variation of concentration $V_{N i}$, in which, after the friction on the abrasive is the transformation of metastable austenite to martensite deformation. The volume of transformation $(\Delta \gamma)$ in materials by the friction with nanosized alloying additions was $30 \%$, and was 10 $\%$ in material with micro powders; analogically thus, the greater was the amount 
TABLE 2: Coefficients of the Evenensen equation $V=V_{=}(q m \tau+1)^{-1 / m}$ and activation energy of sintering at $900{ }^{\circ} \mathrm{C}$ for iron-based powder systems.

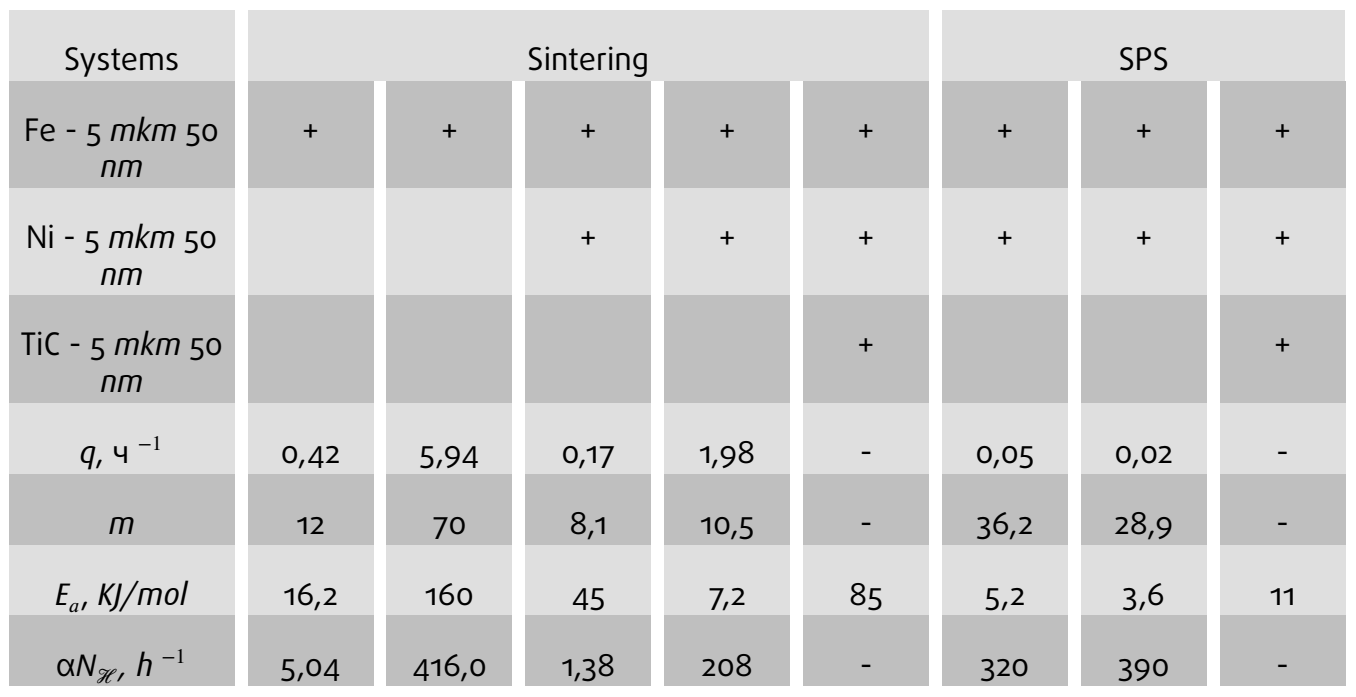

of transformation, the higher was the hardness, microhardness and wear resistance, tab.3.

After friction on the abrasive, metastable austenite was transformed into a martensite of deformation-in materials with nanodispersed doping additives, the volume of $\Delta y$ was $30 \%$, and with a microdisperse $10 \%$, Table. 3 . In the material with nanodispersed additives of nickel and titanium carbide powders, hardness, microhardness and wear resistance were higher, Table. 3 , due to the fine grain and large volume of the phase transformation.

The maximum value of the grinding coefficient $(K)$ for corundum in a matrix of a diamond tool with microdispersed additives was 25 , and with nanodispersed - 50 , Fig.

2.

TABLE 3: Volume of transformation and physical and mechanical characteristics of sintered materials.

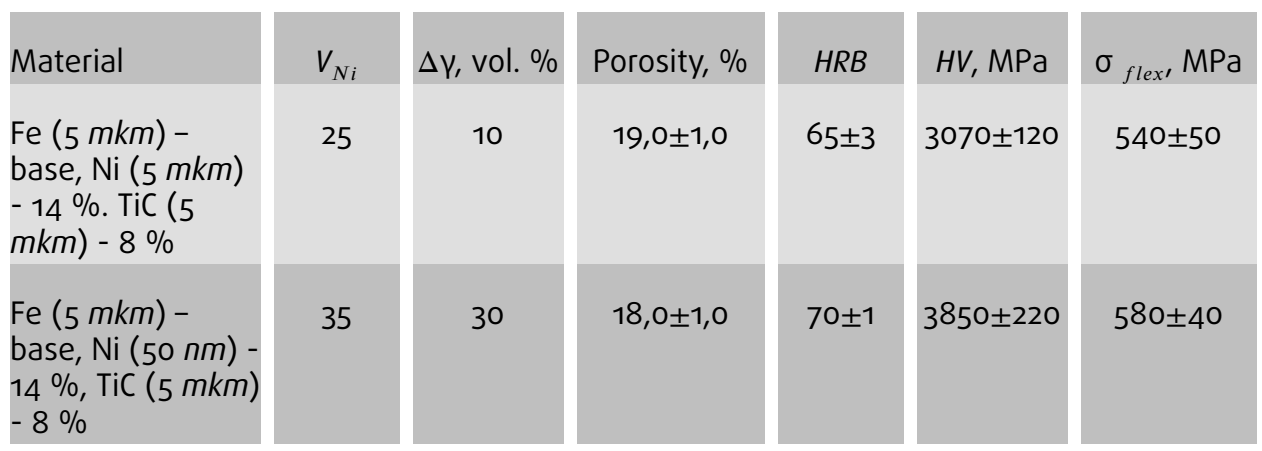

Moreover, the dependencies on the time of work were different: in an instrument containing nanodispersed nickel powder, $\mathrm{K}$ was the maximum section at the initial time, which may be due to the high degree of non-homogeneity of the metastable 


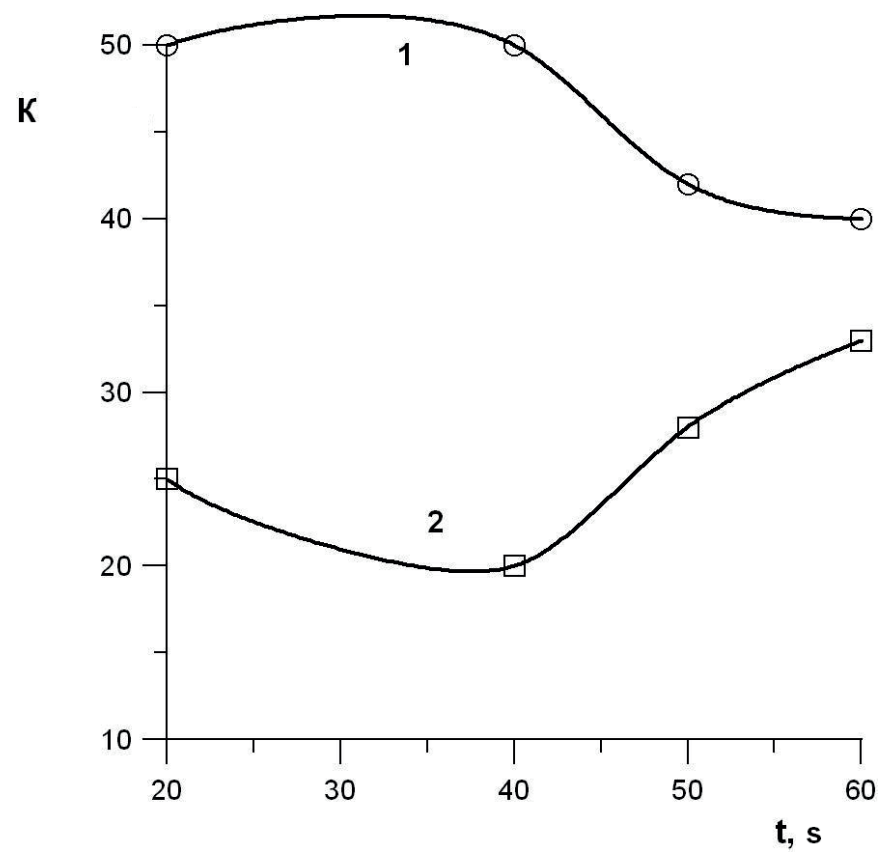

Figure 2: Change in the grinding coefficient of the diamond tool with the time of work on corundum: 1 contains nanodispersed nickel powder 2 - contains microdispersed nickel powder.

austenite and the instantaneous onset of the phase transformation; in an diamond tool containing a microdispersed nickel powder, $K$ was at a 2 -time lower value than case (1), which may be due to the need for an incubation period to initiate the decay of a metastable austenite, probably more homogeneous than austenite (1), then, with increasing friction time, the section increased to 33. The groove was proportional to the volume of the phase transformation for all materials under identical test conditions with the same chemical composition, differing in the degree of inhomogeneity due to the parameters of the sinter and dispersible powders, Fig. 3.

\section{CONCLUSION}

The SPS of the "Fe-Ni" powder systems provides, at lower temperatures and a $5^{-}$ minute isothermal holding time, an increase in the diffusion coefficient $D$ by an order of magnitude or more, compared to free sintering.

The addition of nanodispersed nickel powder to the micron powder of iron reduces the activation energy of sintering several times. The use of SPS for the system of iron-nickel powders significantly reduced the activation energy of sintering. When the powder of titanium carbide is added to the system of iron and nickel powders, the activation energy of sintering increases by a factor of 10 with free sintering, in view of the reduction in the area of the metal contact, and in the case of the SPS, only by a factor of 2 times. 


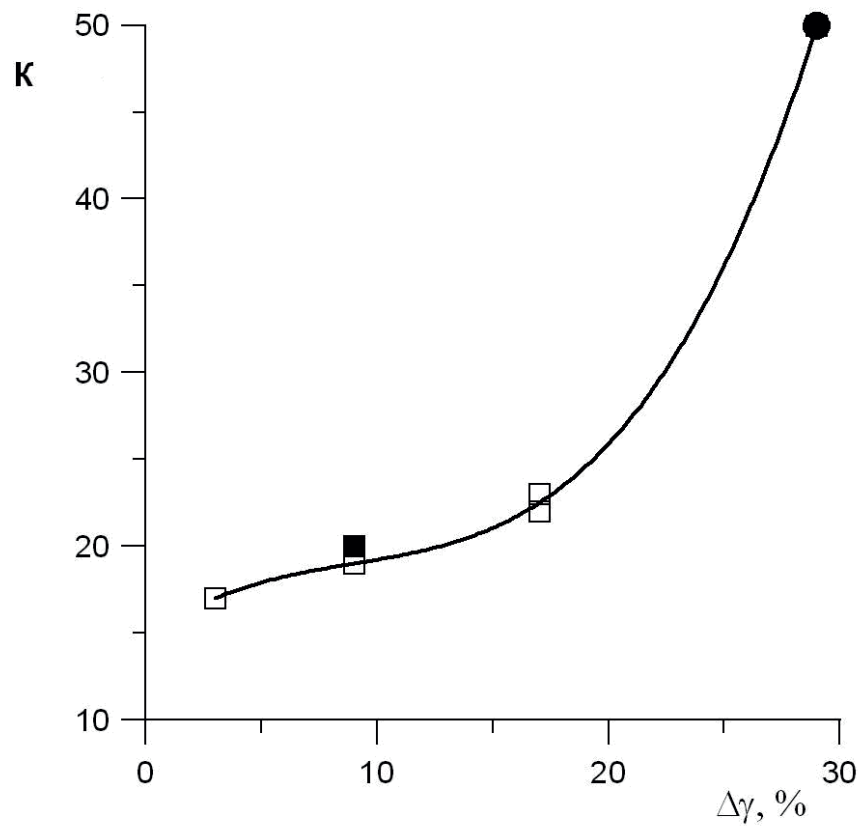

Figure 3: Dependence of the grinding coefficient of the diamond tool (for a friction time of $40 \mathrm{~s}$ ) • contains nanodispersed nickel powder $\square, \mathbf{a}$ - contains microdispersed nickel powder, $\square$ - data [5].

In the SPS process, as in free sintering, in the carbide steels of the "iron-nickeltitanium carbide" system, a non-homogeneous ferrite-austenite structure is formed in which, after abrasion friction, a metastable austenite is converted into a martensite of deformation. The dependence of the grinding coefficient of the diamond tool on the volume of the phase transformation of the metastable austenite into the martensite of deformation is established. The grain size when using nanodispersed powders of nickel and titanium carbide was 2 times less, which led to increased values of physicomechanical characteristics of the materials. The use of nanodispersed nickel and titanium carbide powders to fabricate a matrix of a diamond tool "Fe-Ni-TiC-C (diamond)" by plasma spark-sintering has resulted in an increase in the physicomechanical, tribological and cutting properties of the material due to the increased volume of phase transformation of metastable austenite in martensite deformation.

\section{ACKNOWLEDGMENTS}

The work is executed at support of RFBR grant No. 16-48-590224.

\section{References}

[1] Vereshchagin V A, Zhuravlev V V 1991 Composite diamond-containing materials and coatings. Minsk: Science and Technology 208. 
[2] Zaitsev A A, Kurbatkina V V, Levashev E A 2008 Izv. High schools. Nonferrous metallurgy Peculiarities of the influence of nanodispersed additives on the sintering process and properties of powdered cobalt alloys 2 57-59.

[3] Alymov M I 2007 Powder metallurgy of nanocrystalline materials 169.

[4] Anisimov A G, Mali V I 2010 FGV Investigation of the possibility of SPS of powder nanostructured materials 46(2) 135-138.

[5] Bugrov Yu V, Protsiv Yu V 2011 Metallurgy and thermodeformation processing of special steels and alloys: a set of teaching 130.

[6] Shatsov A A, Ryaposov I V 2010 Metallurgy and heat treatment of metals Concentration-inhomogeneous nickel-molybdenum trip-steel 11 47-50.

[7] Oglezneva S A 2011 Friction and wear Diamond tool on a steel metastable binder for cutting natural stone 32(4) 409 - 414. 